\title{
Economic Reforms and the Indirect Role of Monetary Policy
}

\author{
Andrea Beccarini ${ }^{\dagger}$
}

$25 / 2012$

${ }^{\dagger}$ Department of Economics, University of Münster, Germany

wissen.leben

WWU Münster 


\title{
Economic reforms and the indirect role of monetary policy
}

\author{
Andrea Beccarini, \\ Westfälische-Wilhelms Universität Münster, Institut für Ökonometrie und Wirtschaftsstatistik, Am \\ Stadtgraben 9, 48143, Münster (DE). E-mail: 05anbc.wiwi.uni-muenster.de
}

\section{Abstract}

Due to pressure from some lobbies, the government is unwilling to perform structural reforms. The probability of its reelection depends, however, on a positive business cycle. The central bank may create surprise deflation even though it maximizes the public's utility function and even if it faces a rational market. This may explain why the ECB, but not the US FED, is found to be unaffected by the inflation bias.

JEL: E32, E58.

Key words: Political Business Cycles, Time Inconsistency of Monetary Policy

\section{Introduction}

The existing literature modeling a central bank's conduct of monetary policy seems unsuited to explaining the approach of some central banks towards governments that do not significantly perform structural economic reforms. In fact, on the one side, the literature regarding the time-inconsistency of monetary policy states that the central bank (even if independent) may wish to create surprise inflation in order to stabilize output around a level that exceeds the natural rate of output. See the model of Barro and Gordon (1983). This is due to the fact that the natural output is undesirably low due to some distortions in the economy such as imperfections in the products or labour markets. This higher target level may also stem from political pressures on the central bank. According to this strand of literature, the central bank aims to reach only a second best by creating surprise inflation where the first best consists of removing the economic inefficiencies. On the other side, for example, the ECB has always attempted to create a consensus through its official communications about the need to implement structural reforms and, particularly in recent times, it has promoted some policy interventions such as the Security Market Programme $^{1}$ (SMP) only conditional on the implementation of some structural reforms ${ }^{2}$. The ECB has also been participating with the International Monetary Fund and European Commission in the bargaining process with the Greek government for the financial bailout of Greece, making the implementation of economic reforms a condition for the granting of financial aid. All these facts show that the ECB is not pursuing the second best; instead, it seeks to use its bargaining power in order to compel governments to remove the economic inefficiencies.

Against this background, this work shows that an independent central bank, even though it shares the public's view about the importance of employment and inflation, may find it optimal to create surprise deflation rather than surprise inflation as the literature of time-inconsistency postulates. This is because,

\footnotetext{
${ }^{1}$ The Security Market Programme is defined as "Interventions by the Eurosystem in public and private debt securities markets...", see the ECB web side.

${ }^{2}$ The ECB wrote an official letter to the Italian government in the summer of 2011 indicating urgent policies aimed at increasing the potential output. Furthermore, in the press conference of 3 November 2011, ECB president Draghi hinted that the purchase of (Italian) government bonds within the SMP is conditional on the implementation of the indicated reforms.
} 
once the government has some reluctance to implement structural reform, it is optimal for society as a whole to reduce its probability of reelection. The public cannot remove this government before the next election; during this election, however, differently from the central bank, the public has limited information about the government performance. Indeed, there is abundant literature reporting a number of reasons why the government is reluctant to implement structural reforms. For a survey, see Leiner-Killinger et al (2007) and references therein. This work is also related to the literature of political business cycles, see, for example, Rogoff and Sibert (1988).

\section{The model}

One considers the model of Fratianni et al (1997) connecting the theory of political business cycles, as in Rogoff and Sibert (1988), with the monetary policy conduct of different types of central banks, including that assumed in Barro and Gordon (1983). In this work, one modifies the Fratianni et al model by assuming a strategic game between an independent central bank and the government (and the market).

One assumes that each government in charge is biased towards economic expansion since its probability of (re)-election positively depends on the output gap but not on the excess inflation. Furthermore, immediately after the election, the government is subject to a certain degree of control from lobbies aiming to hinder the implementation of structural reforms. This degree of control is a random variable. The central bank sets its monetary policy after having observed the elections and the lobbies. Due to the presence of the market imperfections, the monetary policy is affected by the inflation bias but, at the same time, the central bank has the incentive to hinder a positive business cycle when the government is heavily controlled by lobbies. Without a positive business cycle the government faces a trade-off as it must choose the amount of reforms to balance its probability of reelection with the compliance to the lobbies.

Elections occur every other two periods. At the period of election (say $t, t+2, .$. ) the following facts occur:

- The market sets its expectations on inflation.

- The central bank sets its monetary policy.

- The government is elected.

- The degree of control from lobbies is established randomly.

- The government implements its economic policy.

At the periods of non-elections the third and the fourth points do not occur. Since the market, the central bank, and the government are rational, they use the principle of backward induction to make their optimal decisions - a three players strategic game occurs. In other words, when a government of this kind is added to the Barro and Gordon model, the central bank has an incentive to create surprise deflation in order to remove lobbies from the government, and the market should consider this in setting its expectation on inflation.

The power of lobbies on the government is random variable $\bar{L}_{t}$ drawn from a known (identically and independent) distribution in periods $t, t+2, \ldots$ The public and the market do not observe the realization of this variable, whereas the government and the central bank do. When setting monetary policy, the central bank maximizes the public's utility function considering that the surprise inflation affects the next election and that, after this election, a new degree of lobbies occurs. If, for example, the realization of $\bar{L}_{t}$ is above 
its average and hence the government is reluctant to perform structural reforms, the central bank has the incentive to create surprise deflation in order to decrease the probability of the government's reelection ${ }^{3}$.

As in Fratianni at al (1997) the economy is affected by supply shocks. These, in turn, may stem either from an exogenous source or from the government's economic policy. The structure of the economy is the following:

$y_{t}=y_{t}^{*}+\left(\pi_{t}-\pi_{t}^{e}\right)+u_{t}$

$y_{t}^{*}=y_{t}^{n}+u_{t}$

$u_{t}=\eta_{t}+\rho_{t}$

where $y_{t}$ is the real output, $\pi_{t}$, the rate of inflation, $\pi_{t}^{e}$ the expected rate of inflation. For the sake of simplicity, the central bank is assumed to control fully the actual inflation. The variable $y_{t}^{*}$ is the full information level of output that would prevail in the absence of wage contracts and $y_{t}^{n}$ is the natural level of output. The variable $u_{t}$ is the aggregate supply shock, $\eta_{t}$ is the policy shock and $\rho_{t}$ is the exogenous shock. Differently from the Fratianni et al model, $\eta_{t}$ does not depend on competence but on willingness to perform structural reforms which ultimately depends on the compliance of the government to the lobbies, $L_{t}$ such that:

$\eta_{t}=\eta\left(L_{t}\right) ; \eta^{\prime}\left(L_{t}\right)<0$

The public utility function is the following:

$U S_{t}=y_{t}^{*}-\frac{b_{0}}{2}\left[\left(\pi_{t}-\pi_{t}^{e}\right)+\left(\eta_{t}+\rho_{t}\right)\right]^{2}-\frac{b_{1}}{2}\left(\pi_{t}-\pi^{T}\right)^{2}$

The public benefits from a higher level of full information output, but suffers from deviations around that level of output and from the variability of inflation around its predetermined target, $\pi^{T}$.

The utility function of the government is the following:

$U G_{t}=P G_{t}\left[k+g\left(L_{t}-\bar{L}_{t}\right)\right]+\lambda U S_{t}$

Where $P G_{t}$ is the probability of (re)-election which equals one in non election periods and $P G_{t}=$ $f\left[\left(\pi_{t}-\pi_{t}^{e}\right),\left(\eta_{t}+\rho_{t}\right)\right]$ during elections. In this case, it positively depends on surprise inflation and supply shocks. The parameter $k$ is the pay-off from being in office, $g\left(L_{t}-\bar{L}_{t}\right)$ is the lobby's welfare function, increasing in $L_{t}-\bar{L}_{t}$, where $\bar{L}_{t}$ can be interpreted as the required compliance of lobbies (and $L_{t}$ is the deliberate compliance of the government towards these lobbies). $\lambda$ is a non negative parameter indicating the importance of social welfare to the government.

Now, one solves the maximization problems for the government, central bank and market, respectively, and according to the principle of backward induction.

\footnotetext{
${ }^{3}$ If the government's utility function includes the welfare function, the government should also consider the decrease of this function once the central bank creates surprise deflation.
} 


\subsection{The government maximization problem}

The government chooses $L_{t}$ after observing $\bar{L}_{t}$ taking into consideration that $g_{L_{t}}^{\prime}\left(L_{t}-\bar{L}_{t}\right)>0, \eta^{\prime}\left(L_{t}\right)<$ 0 and the other constraints implied by the economy. Note that the government takes actual and market expectations as given.

$\frac{\partial U G_{t}}{\partial L_{t}}=\frac{\partial P G_{t}}{\partial \eta_{t}} \frac{\partial \eta_{t}}{\partial L_{t}}\left[k+g\left(L_{t}-\bar{L}_{t}\right)\right]+P G_{t} \frac{\partial g\left(L_{t}-\bar{L}_{t}\right)}{\partial L_{t}}+\lambda \frac{\partial \eta_{t}}{\partial L_{t}}\left[\left(\pi_{t}-\pi_{t}^{e}\right)+\left(\eta_{t}+\rho_{t}\right)\right]=0$

The above first order condition states that when, for example, decreasing $L_{t}$, the government must balance the increase of the probability of reelection with the decrease of the lobby's welfare function and with the increase of society's function ${ }^{4}$.

In order to find a closed form solution one must consider the first-order approximation of the function ${ }^{5}$ $P G_{t}$ :

$P G_{t}=a+c\left(y_{t}-y_{t}^{n}\right)$

One also assumes that $g_{L_{t}}^{\prime}\left(L_{t}-\bar{L}_{t}\right)=m$ and $\eta^{\prime}\left(L_{t}\right)=-n$

where $a, c, m$ and $n$ are positive constant parameters. These assumptions allow one to find a closed form solution for $\eta_{t}$ (or $L_{t}$ ) after simple maths:

$\eta_{t}^{*}=-\left(\beta_{1}+\beta_{2}\left(\pi_{t}-\pi_{t}^{e}\right)+\beta_{3} \bar{L}_{t}+\beta_{4} \rho_{t}\right)$

where $\beta_{i} i=1, . ., 4$ are all positive parameters. The optimal level of structural reforms negatively depends on the surprise inflation, on the control of lobbies and the exogenous supply shock.

It is worth stressing some properties of the surprise inflation parameter, $\beta_{2}$ :

$\frac{d \beta_{2}}{d m}>0 ; \frac{d \beta_{2}}{d c}>0 ; \frac{d \beta_{2}}{d n}<0 ; \frac{d \beta_{2}}{d \lambda}<0 ;$

Should the importance of the lobby's welfare function $m$ increase, the optimal level of reforms should decrease, given a particular amount of surprise deflation.

\subsection{The central bank's maximization problem}

The independent central bank maximizes the public's utility function by steering the actual inflation, subject to the government reaction function. The closed form solution for the optimal inflation is:

$\pi_{t}^{*}=-\gamma_{0}+\gamma_{1} \pi_{t}^{e}+\gamma_{2} \pi^{T}+\gamma_{3} \bar{L}_{t}+\gamma_{4} \rho_{t}$

where $\gamma_{0}, \gamma_{1}, \gamma_{2}$ and $\gamma_{4}$ are positive parameters ${ }^{6}$ and $\gamma_{3}$ is a negative parameter ${ }^{7}$. The quantity ${ }^{8}\left(-\gamma_{0}\right)$ is a function of $\beta_{2}$ such that $d \gamma_{0}\left(\beta_{2}\right) / d \beta_{2}>0$ and $\gamma_{0}=0$ if $\beta_{2}=0$. It represents a negative component of the optimal inflation due to the presence of some lobbies' control of the government. Note that, as in the

\footnotetext{
${ }^{4}$ This first order condition holds in elections periods $(t, t+2, .$.$) . In order to find the f.o.c. in non elections periods, set$ $P G_{t}=1$ in eq. 6).

${ }^{5}$ Around a null value of the output gap.

${ }^{6}$ Provided that $\mathrm{b}_{0}\left(1-\beta_{2}\right)^{2}-\mathrm{b}_{1}>0$

${ }^{7}$ Provided that $\beta_{2}>1$

${ }^{8}$ Absent in the standard time-inconsistency models.
} 
Barro and Gordon model, the inflation bias is present but under suitable values of $\beta_{2}$ this bias can be neutralized.

\section{Conlcusion}

When economic inefficiencies are due to the presence of some lobbies controlling the government, the independent central bank will realize that it can use its monetary policy to penalize this government through negative business cycles. This stance towards the political business cycles may offset the inflation bias. Considering that the European economy is affected by several economic inefficiencies with respect to the US economy, this may clarify why the ECB (but not the FED) is found to be unaffected by the inflation bias.

\section{References}

Barro, R.J., Gordon, D.B., 1983. A positive theory of monetary policy in a natural rate model. J. Polit. Economy 91, 589-610.

Fratianni, M., Von Hagen, J., Waller, C., 1997. Central banking as a political principal-agent model. Econ. Inquiry 35,378-393.

Leiner-Killingner, N., Peréz, V. L., Stiegert, R., Vitale, G., 2007. Structural Reforms in EMU and the role of monetary policy. ECB Occasional Paper No. 66.

Rogoff, K., Sibert, A., 1988. Elections and macroeconomic policy cycles. Rev. Econ. Stud. 55, 1-16. 